\title{
Predictability of coral bleaching from synoptic satellite and in situ temperature observations
}

T. R. McClanahan - M. Ateweberhan •

C. Ruiz Sebastián · N. A. J. Graham · S. K. Wilson •

J. H. Bruggemann · M. M. M. Guillaume

Published online: 13 July 2007

(C) Springer-Verlag 2007

\section{Erratum to: Coral Reefs}

DOI 10.1007/s00338-006-0193-7

In the printed and online version of the article the sentence describing, and the formula for susceptibility should have read as follows:

The site-specific bleaching susceptibility index (BSI) was determined from the taxon-specific BR and multiplying this response by its relative density and summing for all taxa at the site, according to Eq. 2.

$\mathrm{BSI}=\sum_{i=1}^{N} \mathrm{BR}_{i} \times D_{i}$

where $i$ is an individual taxon, $D$ is the relative density of the taxon and $N$ is the total number of taxa.

The online version of the original article can be found under doi:10.1007/s00338-006-0193-7.

T. R. McClanahan ( $₫)$

Wildlife Conservation Society, Marine Programs,

Bronx, NY, USA

e-mail: tmcclanahan@wcs.org

M. Ateweberhan

Coral Reef Conservation Project,

P.O. Box 99470, Mombasa, Kenya

C. Ruiz Sebastián

Advanced Research Center for Applied Microbiology,

University of the Western Cape, Belville, South Africa

N. A. J. Graham · S. K. Wilson

School of Marine Science and Technology,

University of Newcastle,

Newcastle upon Tyne NE1 7RU, UK
S. K. Wilson

Australian Institute of Marine Science, TMC,

Townsville, QLD 4810, Australia

J. H. Bruggemann - M. M. M. Guillaume

Laboratoire d'Ecologie marine (ECOMAR),

Université de la Réunion, B.P. 7151,

97715 Saint-Denis ms cx 9, La Réunion, France

M. M. M. Guillaume

Département des Milieux et Peuplements Aquatiques,

UMR 5178 CNRS-UPMC-MNHN,

Muséum National d'Histoire Naturelle,

61 rue de Buffon, 75005 Paris, France 